\title{
Processos, modos e mecanismos da identificação entre o sujeito e a(s) língua(s)
}

Maria Onice Payer(UNIVÁS)

\section{Resumo}

Este artigo apresenta resultados de pesquisa que tem como objeto de investigação os processos de identificação que envolvem a relação sujeito/ língua(s), seus modos de constituição e seus mecanismos de aparecimento no discurso. São observados sobretudo processos da prática de ensino-aprendizagem de lingua materna. Localizamos e descrevemos diferentes modos e mecanismos específicos pelos quais as relações entre o sujeito e a forma material da lingua formadas na história funcionam discursivamente, na atualidade, em um nivel constitutivo, e se marcam na materialidade da linguagem. O objetivo é precisar o funcionamento dessas identificações de modo a contribuir com o trabalho sobre a linguagem na prática do ensino de língua.

Palavras-chave: identificação; sujeito; ensino; lingua materna; discurso. 


\section{Introdução}

Este artigo resulta de preocupações que vêm sendo trabalhadas em estudos e pesquisas mais amplos, que têm como objeto de investigação a relação sujeito/língua(s) ${ }^{1}$, especialmente os processos de identificação que ocorrem envolvendo essa relação, seus modos de constituição e seus mecanismos de aparecimento no discurso. Neste texto expomos alguns resultados de pesquisa que se vão delineando sobre o funcionamento dessas identificações entre o sujeito e as línguas específicas e/ou formas da língua diversas, sobretudo na prática de ensino-aprendizagem de língua materna ${ }^{2}$. Nos processos de identificações com a língua nessa prática, localizamos e descrevemos diferentes modos e mecanismos específicos pelos quais as relações entre o sujeito e as (formas das) línguas produzidas na história, envolvendo eventos com a língua, funcionam discursivamente na atualidade, em um nível constitutivo, e se marcam na materialidade da linguagem.

Nosso objetivo é precisar o funcionamento dessas identificações de modo a contribuir com o trabalho sobre a linguagem na prática do ensino de língua, bem como em outras práticas em que a acuidade com a língua e os sentidos seja relevante. Para isso, vamos sistematizar os mecanismos discursivos observados no aparecimento dessa relação sujeito/língua, e também vamos expor uma direção de trabalho que se vem esboçando com os sujeitos, considerando a história em que as relações com a(s) (formas das) língua(s) se estabeleceram.

\section{A questão}

Em certo sentido, a questão da identificação do sujeito à língua, como correlata da interpelação, encontra-se no cerne da semântica discursiva em que as noções de sujeito, historicidade e ideologia se impõem à consideração da língua, sobretudo em seus aspectos sintático e lexical, enquanto base linguística dos processos discursivos (PÊCHEUX, 1975; 1988). Por outro lado, a noção de identificação, quando mobilizada relativamente ao quê e ao como se ligam o sujeito e determinadas formas materiais da língua (ORLANDI, 1996), conforme vamos trabalhar adiante, adquire

Projeto Discurso, Memória e Ensino de Língua, vinculado ao Grupo de Pesquisa Práticas de Linguagem, Memória e Processos de Subjetivação, cadastrado no Diretório de Pesquisa do CNPq.

2 Agradeço à FAPEMIG pelo apoio à apresentação e discussão destes resultados desta pesquisa no XXVII Encontro Nacional da ANPOLL - UFF, Niterói, 10 a 13 de julho de 2012. outros sentidos, que a especificam teoricamente, ao mesmo tempo em que abrem semanticamente para a direção de compreender o funcionamento desta identificação especificamente na relação do sujeito com a(s) língua(s), no sentido de línguas específicas, variedades de língua e formas materiais distintas, onde o que está em jogo é a pluralidade de efeitos de sentido que se produzem por/ em uma forma linguística ou outra, bem como o efeito-sujeito (de língua) que delas resulta.

Na primeira acepção entende-se o funcionamento da identificação sujeito/sentido que se ressalta no cerne da análise de discurso, quando M. Pêcheux (1988) assinala à Linguística, pela 
filosofia espontânea do sujeito que a acompanha, o fato de que o indivíduo não é fonte de seus sentidos, e de que "a 'evidência' da identidade oculta que esta resulta de uma identificação-interpelação do sujeito, cuja origem estranha é, contudo, 'estranhamente familiar'" (PÊCHEUX, 1988, p. 155). Na direção da segunda acepção, procuramos trabalhar sobre os processos de identificação em que a língua, sua forma específica em relação ao conjunto de línguas e de formas, se expõe também como algo que participa da construção do objeto do discurso, onde o processo de significação incide sobre e advêm especificamente da materialidade linguística historicamente instalada, de seus sentidos socialmente aceitos como memória e de seus efeitos no sujeito, no seio dos processos de significação. Nesta acepção, a identificação do sujeito em relação às línguas e às suas diferentes formas, como parte do processo de significação, volta-se de modo peculiar sobre a base linguística, assinalando pontos nessa materialidade em que a relação do sujeito com o sentido - a significância - encontra-se em dependência direta de uma impressão de coincidência (ou não) com a forma material.

M. Pêcheux (1969) assinalou o valor das imagens que os sujeitos do discurso se fazem de si e do interlocutor como parte fundamental do fato discursivo, chamando a atenção para que também o objeto do discurso (referente) seja compreendido como um objeto imaginário, de onde resultam as diferenciações e disputas entre formações discursivas que instituem e fazem circular os diversos referentes. Nesse sentido, o que está em questão quando se fala em identificação na relação sujeito/língua(s) pode ser indicado ao se pensar, com o autor, que também em torno do "código" (língua) há imaginários funcionando, de modo que a imagem que os sujeitos fazem da(s) língua(s) e das variadas formas em que o objeto do discurso é dito, participa igualmente da produção dos efeitos de sentido, da construção discursiva do referente, assim como do efeito-sujeito em seu perfil linguístico.

\section{Referencial teórico e antecedentes}

Trabalhamos no campo da análise de discurso de orientação francesa, em sua relação constitutiva com o materialismo histórico e a psicanálise. Como dispositivo analítico operamos, fundamentalmente, com a noção de forma material da língua tal como elaborada por Orlandi (1996), para quem a noção de estrutura permite transpor o limiar do conteudismo, mas ela não basta, pois faz estacionar na ideia de organização, de arranjo, de combinatória. Segundo a autora,

"é preciso uma outra noção. Esta noção, a de materialidade, nos leva às fronteiras da língua e nos faz chegar à consideração da ordem simbólica, incluindo nela a história e a ideologia. Foi, sem dúvida, a crítica feita ao conteudismo - enquanto perspectiva teórica (filosófica) que mantinha, apesar do estruturalismo (ou justamente por ele), a separação estanque entre 
forma/conteúdo - que nos abriu a possibilidade de [...] pensar não a oposição entre forma e conteúdo, mas trabalhar com a noção de forma material, que se distingue da forma abstrata e considera, ao mesmo tempo, forma e conteúdo enquanto materialidade. [...] na língua, tem-se a forma empírica ("pata"), a forma abstrata (p/b) e a forma material (linguístico-histórica, ou seja discursiva)" (ORLANDI, 1996, p. 46-49).

Trabalhamos também com a noção de silêncio, constitutivo e local (ORLANDI, 1992), e de memória, como memória discursiva, como interdiscurso e enquanto base que regulariza materialidades discursivas complexas (PÊCHEUX, 1988; 1999), e como memória do dizer (ORLANDI, 1999); memória do enunciado (COURTINE, 1999); memória da/na língua e as dimensões materna e nacional que revestem as línguas (PAYER, 2006, 2007, 2011; RÈVUZ, 1998), bem como a noção de processos subjetivos investidos na inscrição do sujeito em uma língua estrangeira (CELADA, 2001, 2011).

Também consideramos a história das ideias linguísticas e a constituição da língua nacional no Brasil (AUROUX, 1992; ORLANDI, 2001; ORLANDI e GUIMARÃES, 1996) em que se descrevem processos de gramatização e de institucionalização das línguas no mundo e o modo como os processos históricos ocorrem na relação do Estado e da sociedade brasileiros com a língua, com interpretações advindas de perspectiva teórica não propriamente histórica, mas discursiva, semântica e da própria área da história das ideias. Esta abordagem possibilita observar lugares e modos sócio-históricos e políticos da produção científica sobre a língua, assim como suas representações e discursos sobre a língua que se vão produzindo na história e configurando as práticas de linguagem, incluindo o ensino (ORLANDI E GUIMARÃES, 1996; ORLANDI, 2009; MARIANI, 2004).

Nesse campo teórico e no contexto dessa discussão envolvendo o discurso, a historicidade e a(s) língua(s), a pesquisa em que se estabeleceram as bases para configurar um campo de questões sobre a memória discursiva, as identificações e a língua, de nossa parte, incidiu sobre a memória da língua da imigração italiana no Brasil, passando pelas intercorrências políticas e ideológicas em torno do nacionalismo na década de 1930, que resultaram em uma forte tensão entre a língua nacional brasileira e as línguas maternas dos imigrantes, o que culminou na interdição destas últimas e consequentemente interferiu na constituição desses sujeitos de lingua(gem). Por essa via tenho estudado a noção de memória discursiva (o interdiscurso, a memória do dizer, a condição do legível) pensando-a relativamente à língua. Esses estudos permitiram configurar um campo de questões que especificam o processo de identificação dos sujeitos em relação à língua, seja como língua materna, seja como língua nacional, segundo uma modalidade própria de identificação que é a que se dá em torno da memória da/na língua (PAYER, 2006). 
Assim considerados, pelos processos discursivos observados, transcorridos na história dos sujeitos, produzem-se certos fatos de linguagem que se compreendem como decorrentes dos processos de identificação que se dão na história da relação sujeito/ língua(s), envolvendo acontecimentos como o silenciamento de uma língua no domínio público, a sua permanência no domínio privado, pelo que ela pode vir a ocupar lugares específicos no simbólico, pelas vias tanto da memória discursiva sobre a língua, quanto da memória na língua ela mesma, em estruturas transformadas, que se vêm apresentar nas franjas (traços, marcas) da língua materna apagada.

Em pesquisas anteriores descrevemos alguns processos de identificação sujeito/língua(s) através de eventos na linguagem, como o riso que acompanha enunciados em dialetos, o canto na língua dos antepassados, a denegação dessa língua na constituição linguística do sujeito, a ultracorreção em língua nacional e as marcas de dialetos italianos nos mais diversos níveis da língua, em que atua certa memória e identificação a outra língua ("passada"): na memória fonética, morfológica, semântica, lexical, sintática, em expressões e em fragmentos isolados nas conversações cotidianas (PAYER, 2003; 2006).

Estudando os processos identificatórios na inserção em segundas línguas, Serrani-Infante (1998) observa que essa inserção se dá também em discursividades da língua alvo, uma vez que sentidos encontram-se instalados na língua anteriormente (interdiscurso). Trabalhando com conceitos da análise de discurso e da psicanálise, a autora considera a identificação como "a condição instauradora, a um só tempo, de um elo social e de um elo com o objeto de desejo do sujeito" (SERRANI-INFANTE, 1998, p. 252). Nesse sentido, ressalta que "aquilo que está em jogo, sempre, numa língua ou em outra, é dizer-se a própria verdade de sujeito do discurso e do inconsciente, e isso será o determinante no acontecimento da aquisição e suas implicações identitárias" (Idem, p. 258). Citando O. Mannoni', observa que "uma identificação é uma captura. Aquele que se identifica talvez creia que está capturando o outro, mas é ele quem é capturado" (Idem, p. 253).

Entendemos que os processos de identificação entre o sujeito e a(s) línguas envolvem também lugares de interpretação do sujeito e a sua relação com as imagens das línguas e as dimensões (materna, nacional, estrangeira) que elas ocupam relativamente à história, tais como as imagens e dimensões de língua materna, estrangeira, de imigrante, indígena, de prestígio, popular, etc. Participam da formação dessas imagens que presidem os processos de identificação os movimentos das políticas de línguas, nas práticas discursivas como a propagação, a injunção, a interdição e o silenciamento das línguas, pelas situações de conflito e tensões entre a língua materna e a nacional, situações de apego ou desprendimento, de passagem pelo sujeito de uma língua a 
outra, como nas imigrações, refúgios e exílios, sempre segundo condições de produção específicas.

A propósito desses eventos e relações com a língua, lembramos a elaboração de C. Révuz (1998) segundo a qual a língua "não é e nunca será totalmente dissociável do modo singular pelo qual ela foi encontrada através das falas das pessoas a seu redor". A língua "é vivenciada, intimamente, como uma língua que diz o prazer ou o reprova, uma língua que desfere a verdade sobre o mundo e as pessoas ou que, pelo contrário, deixa um espaço para algo não-sabido, não-compreendido, espaço que a fala do sujeito poderá ocupar" (RÈVUZ, 1998, p. 26). Há razões para considerarmos que também eventos mais contundentes e amplos em relação à língua, tais como a interdição e a desqualificação ou a difusão e o culto imprimem a sua força e as suas marcas a esse "modo singular" pelo qual ela é encontrada pelo sujeito através das falas das pessoas ao seu redor.

\section{Processos, modos e mecanismos da identificação sujeito/língua(s)}

Em algumas práticas de linguagem a relação do sujeito com a(s) língua(s) tal como se formou na história é posta mais diretamente em questão, também como objeto de discurso. Os campos da pedagogia, alfabetização, escrita, ensino de língua estrangeira, materna, literatura, assim como situações de (i)migração são algumas dessas práticas, nas quais vimos observando esta relação, $\mathrm{e}$ de que fazem parte os materiais de análise a que nos dedicamos, constituídos de produções de linguagem oral e escrita, como textos, escritos, leituras, aulas de alfabetização, conversas entre profissionais destas áreas e entrevistas. Nestes materiais analisam-se a relação dos sujeitos com a(s) língua(s) em atividades de linguagem como negociações, diálogos, debates, injunção a dizer, bem como nos aparecimentos circunstanciados de determinados mecanismos que indicam certos modos de identificação com a(s) língua(s). Alguns se manifestam através do riso, ao rir da língua, pela língua; outros no gesto de cantar determinadas canções e músicas em línguas específicas, de imigração ou estrangeiras; na supervalorização da língua; na denegação da presença de dada língua, bem como na ultracorreção, no equívoco e em manifestações de estranhamentos (FREUD, 1919) em relação às formas da língua.

As identificações do sujeito quanto à língua e suas formas materiais se produzem, portanto, em processos constituídos na historicidade dessa relação. A história predispõe assim a relação dos sujeitos com as línguas que se lhe apresentam, enquanto objetos simbólicos, políticos e artísticos. A relação sujeito/língua(s) é atravessada por movimentos de (des)identificação em que se processam semelhanças e diferenças entre formas linguísticas e históricas, estranhamentos e reconhecimentos, aceitações e 
recusas, enfim, movimentos através dos quais vão se instalando, de um modo e não de outro, as (des)identificações entre sujeitos particulares, sempre tomados em uma rede de eventos e relações históricas, e as formas específicas, atravessadas portanto por relações diversas, tensas ou de deleite, admiração e culto (cultivo), especialmente no interior do Estado Nacional Moderno.

Em trabalhos recentes na docência e pesquisa junto a professores de língua(s), vimos observando que no tecido discursivo manifestam-se esses pontos de tensões, de estranhamento ou de adesões em relação à língua, e entendemos essa manifestação como sintoma de algo significativo em relação à história do sujeito com a língua, na formação de um sujeito apto à significação - algo que retorna, indicando um material a ser ouvido, interpretado e trabalhado sobre a relação do sujeito com a língua(gem).

Atentos a essas manifestações, passamos a anotar os modos diversos pelos quais elas irrompem na materialidade discursiva, indicando os pontos a serem trabalhados com os sujeitos específicos sobre o que os constitui nessa relação com a língua.

Assim, para a presente pesquisa, a hipótese de trabalho que se apresenta é a de que esses processos de identificação na relação sujeito/língua(s) vêm manifestar-se no tecido discursivo através de modos e de mecanismos específicos pelos quais se expõem as identificações já constituídas com a língua. Objetivamos circunscrever os modos de relação e mecanismos discursivos desse processo a fim de descrever/interpretar como funciona essa identificação.

Trabalhamos a ideia de que a prática ou a interlocução atual joga um papel importante no aparecimento circunstanciado desses mecanismos. Alguns desses modos e mecanismos pautam-se na materialidade linguístico-discursiva, outros se manifestam em modos discursivos diversos, outras materialidades e outras ordens, tais como a ordem corporal, pelo riso e expressão facial.

Os processos de identificação em relação à(s) língua(s) são constitutivos do sujeito de linguagem, participando da subjetivação no que diz respeito às línguas, bem como à relação que aí se estabelece dos sujeitos com a linguagem, configurada que é por interdições e injunções a uma língua e não outra, a um modo de dizer e não outro. Essas regionalizações linguísticas que recortam o dizível foram observadas por M. Pêcheux (1975), em um sentido um pouco diverso, pela metáfora de que no interior da mesma língua se falam "línguas diferentes", e que em seu texto remete a diferentes formações discursivas no dizer. Podemos retomar essas imagens considerando com o autor que enunciar em uma ou outra língua ou forma material produz inscrição em uma ou outra formação discursiva.

Nos fatos, essas separações (regionalizações) da língua nem ocorrem de maneira tão distinta e linear. É também em uma teia de efeitos de sentidos e posições-sujeito que essas formas se vinculam, se sobrepõem e se (des)ligam. Importa assinalar que 
os efeitos de sentidos que resultam dessas relações do sujeito com as línguas e suas formas diferentes (re)aparecem no tecido do discurso, indicando a densidade dessas identificações produzidas na história e que se reapresentam de algum modo nas atividades de linguagem e na materialidade do discurso.

Esse reaparecimento se dá, pois, de diferentes modos. Ora essas identificações são representadas pelo sujeito, como uma presença/ausência de outra língua, ora aparecem de modo constitutivo, na exterioridade dessa representação, tomadas como evidências da língua, da linguagem, dos sentidos, de uma corporeidade afetada pela significação.

No que se segue, apresentamos algumas situações de linguagem e um esboço de análises em que a identificação sujeito/ língua, tal como está constituída no discurso, vem expor-se na superfície do dizer, manifestando-se de diversos modos.

\section{Situações e análises}

1. Clarice Lispector escreve em uma de suas crônicas a palavra outrem, fazendo-a acompanhada de todo um entorno que diz respeito à relação com a língua, através desta palavra.

\footnotetext{
“entregar-se a pensar é uma grande emoção, e só se tem coragem de pensar na frente de outrem quando a confiança é grande a ponto de não haver constrangimento em usar, se necessário, a palavra "outrem". Além do mais exige-se muito de quem nos assiste pensar: que tenha um coração grande, amor, carinho, e a experiência de também se ter dado ao pensar" (C. Lispector, Brincar de pensar, in A descoberta do mundo. Grifos nossos).
}

Sobre a forma material do português arcaico, onde ele se mescla com o registro em latim (qual o limite entre essas memórias das línguas?), a escritora formula algo sobre a confiança e o constrangimento de enunciar ou não um elemento como este (outrem) na escrita. O sentido de constrangimento mencionado remete ao tema do estranhamento em face das formas da escrita, tal como manifesto por crianças em alfabetização (SOUZA, 2010), que retomaremos adiante. Nesta situação encontra-se portanto um procedimento metaenunciativo (AUTHIER-REVUZ, 1998) sobre a (forma da) língua e seus efeitos.

2. A coordenadora de pós-graduação lato sensu de uma Universidade, sujeito de quem se tem a imagem de experiente e ativo nos campos acadêmico, médico e político, conversa engajadamente ao telefone, explicando ao interlocutor uma situação um pouco complicada, e em dado momento se desculpa de um modo peculiar, com a forma descurpa, com ênfase na variação consonantal pronunciada. Pelo tom engajado da conversa, embora institucional, o pedido de desculpas possivelmente fosse considerado desnecessário para os interlocutores, mas dadas as posições, mesmo assim ele se realiza, parcialmente, como em um jogo em 
que se dissesse: você e eu sabemos que não seria necessário isso, mas pela posição de que estou falando, éo caso de dizer... Essa multiplicidade de sentidos se materializa na substituição da forma desculpa (me desculpa ou desculpa(e)-me) por outra forma que pode ser interpretada como alheia, pronunciada por uma "voz anônima".

Dito desta forma, nesse contexto, o enunciado produz um efeito de ambiguidade e pluralidade entre realizar efetivamente o gesto de se desculpar e indicar que ela sabe que naquela específica relação este gesto seria até certo ponto dispensável. Não é o caso de optar entre um ou outro efeito, pois discursivamente o que tem valor de expertise nessa interlocução está justamente na pluralidade de efeitos com que se enuncia, e que se marca através da simulação de uma forma linguística que a princípio seria diferente da "sua" própria. Outras situações de simulação analisadas assemelham-se à imitação de outro interlocutor, de outra posição discursiva.

3. Crianças em situações de alfabetização, tal como analisadas por Souza (2010), como antecipamos, expressam com frequência seus estranhamentos diante das diferentes formas da língua, as que já sabem e as que devem vir a conhecer na escrita. Uma situação marcante dentre essas manifestações ocorre quando uma das crianças, diante da intervenção corretora da professora alfabetizadora, contra-argumenta: "mas o meu pai fala assim". Souza reflete sobre o modo como a criança explicita, sobre a língua, a observação de que a forma linguística usada por ela (assim como pelo pai, pela mãe, pela comunidade) - e que constitui língua em sua memória discursiva - não seja acolhida pela professora. Trata-se de uma situação em que a criança se depara com a divisão tanto da língua quanto da autoridade de quem institui para ela a língua. Sabe-se que, conforme a teorização lacaniana, a figura paterna representa a lei. Pela análise de discurso, o pai representa uma posição discursiva que funciona na base da imagem de autoridade. Nesta situação está-se diante de um ponto de irrupção do modo como está constituída a relação da criança com a forma da língua, e a resistência a desidentificar-se com essa forma.

4. C. M. da Silva (2012) explicita como os sujeitos procedentes de diferentes processos de imigração (esporádica, esparsa, em massa, do pós-guerra) têm as suas identificações com as línguas materna e nacional afetadas de modos distintos. $\mathrm{O}$ pesquisador observa:

para os imigrantes em massa, que conheceram [...] a interdição de sua língua, não é indiferente falar em português ou em italiano, enquanto para os imigrantes esparsos e dos do pós-guerra, que não conheceram essa interdição pontual, a passagem de uma língua a outra se faz sob o efeito de uma 'naturalidade', como eles dizem. Não há a marca de língua interditada em relação ao italiano como língua materna, tampouco a imagem da língua portuguesa como ligada a um funcionamento jurídico-político (SILVA, 2012, p. 56). 
Nessa situação, nota-se como os acontecimentos linguísticos marcam o sujeito constituindo diferentemente a sua relação com as línguas, de modo a produzir em relação à sua enunciação diferentes efeitos, como o de naturalidade, na evidência da linguagem, e ausência de intervalos de silêncios significativos, indicativos, segundo a interpretação do pesquisador, de intervenções vivenciadas em relação à língua e sua história, como fica ressaltado nas entrevistas com os imigrantes do pós-guerra. Nesta situação podemos destacar, das relações de (des)identificação com as línguas, a irrupção do silêncio, o efeito de naturalidade no dizer e a presença de efeitos jurídico-políticos na enunciação de uma língua ou outra.

5. Consideremos ainda as inúmeras situações de riso que seguem enunciados com formas linguísticas de dialetos de imigrantes - em massa, que se defrontaram com a interdição oficial da língua materna. Junto ao riso ocorre a imitação dos jovens (falantes de português) em relação aos velhos (falantes de dialetos ou com suas marcas acentuadas), numa ambiguidade entre uma identificação carinhosa e a exposição da alteridade linguística. Consideramos que a manifestação do riso diante das formas linguísticas constitui uma manifestação de (des)identificação de outra ordem, uma manifestação corpórea de pontos de tensão, que não passa pelo trabalho da formulação do equívoco pela simbolização da diferença, como vimos formular-se na situação acima analisada ${ }^{4}$.

6. Alunos do ensino médio foram mobilizados para ler crônicas de C. Lispector e em seguida escrever sobre sua leitura (SILVA, 2012). Dentre esses escritos encontram-se sinais de uma identificação constitutiva, na escrita de uma das alunas (Marina), com a leitura da literatura desta escritora, assim como uma imitação de suas formas literárias: a pontuação, a construção sintática, a simulação de uma enunciação cotidiana, entre outros. Apresentamos um fragmento de texto da aluna:

Já ouvi falar, não me lembro quem falou e muito menos quem a escreveu, mas ouvi! E era uma frase que dizia mais ou menos assim "toda felicidade vem embrulhada num fino papel de tristeza." E foi dessa frase que me lembrei lendo a crônica "Medo do desconhecido" de Clarice Lispector. [...] E pensando no que escreveria agora, lembrei-me de uma outra frase de Clarice Lispector "O que sinto não é sempre o que sinto e sim outra coisa". Porque esse não é um texto, são palavras unidas expressando um "pensar". Isso é texto? Sei lá. Mas não quero expressar o que sinto de um modo grosseiro, por isso escrevo agora com o coração. Talvez o mesmo coração que Clarice, acho

4 Desenvolvimentos de análises do riso, da denegação, da ultracorreção e do canto como modos do processo de identificação em língua materna encontram-se em Payer, 2003. que agora ela está em mim e isso me traz felicidade, a mesma felicidade vaga e inexplicável de que ela falava na crônica... (SILVA, 2012, p.100-101).

O texto da aluna indica ainda a formulação de uma relação de intertextualidade em sua relação com a leitura de outros textos 
da autora, bem como uma desidentificação, se não resistência crítica, com o gênero textual da "redação", tema insistente no ensino médio envolvido com a preparação para o vestibular.

Mencionamos acima algumas dentre as muitas e diversificadas situações de linguagem reunidas no corpus da pesquisa, a fim de indicar como se expõem os modos diversos (constitutivos, representados ou de outra ordem, como a corporal) dos mecanismos discursivos que manifestam na materialidade do discurso o funcionamento de um processo de identificação do sujeito em relação à(s) língua(s) e formas linguísticas presentes em sua história e nas práticas discursivas atuais. Podemos sistematizar estes e outros mecanismos, já estudados em outros momentos, em um esquema como o que segue.

1. Procedimentos meta-discursivos sobre língua: comentários, mecanismos meta-enunciativos.

2. Modos não-formulados: equívocos, ironia, lapso, estranhamento, autocensura.

3. Relação não representada com a língua: denegação, ultracorreção, imitação, simulação.

4. Irrupção de ordem corporal: riso, expressão facial, gesto.

5. Formulação representada: explicitação de pontos de identificação e de (des)identificação com a língua.

Não vamos aqui, pelo espaço-tempo deste texto, descrever todos os mecanismos mencionados no esquema acima, que foram e estão sendo objeto de trabalho em outras partes da pesquisa. Apenas gostaríamos de assinalar um modo de organização destas relações, enquanto processos (de identificação), modos (representados ou não, formulados ou não, irrompendo em ordens e materialidades significantes diferentes), e mecanismos pelos quais se manifestam na materialidade discursiva essas (des)identificações (meta-enunciação, ironia, imitação, etc.). Esta organização, ao nosso ver, dá conta de indicar a especificação conceitual da noção de identificação, como dissemos no início, ao abrir para uma direção que a considera, no seio do discurso, na relação do sujeito com a(s) língua(s).

Dentre esses modos e mecanismos, gostaríamos de ressaltar um deles, que ao nosso ver tem um valor crucial para a prática de ensino de língua. Trata-se, no domínio da representação, da formulação desses processos. Consideramos importante que os sujeitos de linguagem possam alcançar essa capacidade de formulação, de modo a poder colocar em palavras, dar linguagem, elaborar esses pontos de (des)identificação que constituem a sua relação com as formas materiais, com os sentidos, como "gestos reconhecidos e não denegados", como diria Michel Pêcheux (1982).

A direção de trabalho em que se está investindo desse modo é de que esses pontos tensos da história dos sujeitos com a(s) língua(s) possam ser trabalhados de modo a se tornarem saberes para o/do sujeito sobre si mesmo e sobre as línguas. Em 
uma história cheia de multiplicidade silenciada como a nossa, há indícios de todo um material de memória das línguas (seus sentidos e seus sujeitos) funcionando de modo subterrâneo, não reconhecido e pouco institucionalizado. O predomínio entre nós do formalismo e do positivismo em termos de história das ideias linguísticas dificulta uma representação mais condizente com os sujeitos simbólicos realmente presentes em nossa história social. Além disso, notam-se marcas impressas nos sujeitos em práticas escolares repressoras sobre a língua, que incidem na sua relação com a linguagem, levando a uma redução dessa relação, na escola, a uma relação com a forma, em detrimento dos efeitos de sentido.

Há uma potencialidade no material simbólico que atua nos subterrâneos, em um e em outro caso, demandando olhar, escuta, atenção e um trabalho qualificado, enfim, sobre as marcas dessas relações. Esse trabalho pode levar esse material a deixar de atuar no obscuro dos sentidos e vir a tomar lugar na superfície do dizer, em formulações expressas e representações "que dizem a própria verdade de sujeito do discurso e do inconsciente", como dizia Serrani-Infante (1998).

Num grau máximo desse trabalho qualificado sobre a relação sujeito/língua, esses pontos de (des)identificação podem vir a ser exercidos politicamente, e também vividos poeticamente, à maneira de $\mathrm{C}$. Lispector, que soube explorar tão bem as suas próprias (des)identificações em relação à língua, aos sentidos, ao mundo "evidente".

\section{Concluindo}

Procuramos circunscrever e precisar o funcionamento discursivo indicado por pontos de irrupção, na materialidade discursiva, da identificação sujeito/língua(s). Para as práticas profissionais com a língua resta avaliar sua operacionalidade analítica, a fim de compreender como está se dando para os sujeitos essa (des)identificação, e como ela pode ser trabalhada para ganhar terreno sobre o não sabido e o não reconhecido em relação à língua. Importa aqui pensar esses processos no ensino: na leitura, na escrita, na elaboração, tanto dos sentidos e do texto quanto do sujeito de linguagem.

Entender os processos, os modos e os mecanismos dessa identificação sujeito/língua pode contribuir para compreender as vicissitudes por que passam os sujeitos no processo de subjetivação, como diz Celada (Payer e Celada, 2011) em sua inscrição na língua. E isso, sobretudo quando outros processos já se instalaram também na relação entre os sujeitos e as línguas através da história. Deste modo se compreende melhor como a língua pode ser posta, no ensino, como objeto não só de conhecimento, mas também de relação e de identificação. 


\begin{abstract}
This article presents the results of a research that has as object of investigation the identification process that involves the connection between the subject and the language(s), its manners of constitution and its appearance mechanisms in the discourse. Above all, situations on the practice of learning-teaching of the mother tongue are observed. We located and described different methods and specific mechanisms through which the connection between the subject and the material form of the language formed in history function discursively, currently, in a constitutional level, and are marked on the language's materiality. The goal is to precise the functioning of these identifications to contribute with the work about language in the practice of language teaching.
\end{abstract}

Keywords: identification; subject; learning-teaching; mother tongue; discourse.

\title{
REFERÊNCIAS
}

AUROUX, S. A revolução tecnológica da gramatização. Campinas: Ed. Unicamp, 1992.

AUTHIER-REVUZ, J. Palavras incertas. As não-coincidências do dizer. Campinas: Ed. Da Unicamp, 1998.

CELADA, M. T. Aspectos da subjetividade do brasileiro especialmente convocados no processo de aprendizagem de espanhol. Sinteses Teses, IEL/UNICAMP, 8, p. 85-99, 2004.

COURTINE, J.-J. Quelques problémes théoriques et métodologiques em analyse du discours, à propos du discours communiste adresse aux chrétienes. Langages, Paris, Larousse, no. 62. 1981.

FREUD, S. (1919) O estranho. In: Edição standard brasileira das obras completas de Sigmund Freud. vol. XVII. Rio de Janeiro: Imago, 1969. GUIMARÃES, E. e ORLANDI, E. Lingua e cidadania. O Português no Brasil. Campinas: Pontes, 1996.

LISPECTOR, C. A descoberta do mundo. Rio de Janeiro: Ed. Rocco, 1999.

MARIANI, B. Colonização linguística. Campinas: Ed. Pontes, 2004. ORLANDI, E. P. As formas do silêncio. No movimento dos sentidos. Campinas: Ed. Da Unicamp, 1992.

Interpretação. Autoria, leitura e efeitos do trabalho simbólico. Petrópolis: Vozes, 1996

Pontes, 1999.

Análise de Discurso. Princípios e procedimentos. Campinas: 
e ensino no Brasil. Campinas: RG Editora, 2009.

ORLANDI, E. P. (Org.) História das ideias linguísticas. Campinas: Ed. Pontes; Cáceres: Unemat, 2001.

PAYER, M. O. Memória da Lingua. Imigração e nacionalidade. São Paulo: Ed. Escuta, 2006.

PAYER, M. O. Modos de aparecimento de uma língua apagada no trabalho do esquecimento. Revista Organon, IL/UFRGS, v. 17, $\mathrm{n}^{\mathrm{o}} .35,2003$.

PAYER, M. O. Processos de identificação Sujeito/língua: Ensino, língua nacional e língua materna. In: ORLANDI, E. P. (Org.). Política linguística no Brasil. Campinas: Ed. Pontes, 2007.

PAYER, M. O.; CELADA, M. T. Relação sujeito/língua(s). Materna, Nacional, Estrangeira. In: As bordas da linguagem. Eliana M. Silveira (Org.). Uberlândia: EDUFU, 2011.

PÊCHEUX, M. (1984) Papel da Memória. In: ACHARD, P. et al. O papel da memória. Campinas : Ed. Pontes, 1999.

PÊCHEUX, M. Análise Automática do Discurso. In: GADET, F.; HAK, T. (Orgs.). Por uma análise automática do discurso. Uma introdução à obra de Michel Pêcheux. Trad. Bethania S. Mariani et al. Campinas: Ed. da Unicamp, 1990.

PÊCHEUX, M. A propósito da Análise Automática do Discurso: Atualização e Perspectivas. In: GADET, F.; HAK, T. (Orgs.). Por uma análise automática do discurso. Uma introdução à obra de Michel Pêcheux. Trad. Bethania S. Mariani et al. Campinas: Ed. da Unicamp, 1990.

PÊCHEUX, M. Semântica e discurso. Uma crítica à afirmação do óbvio. Trad. E. P. Orlandi. Campinas: Ed. da Unicamp, 1988.

RÈVUZ, C. A Língua Estrangeira, entre o Desejo de um outro Lugar e o Risco do Exílio. In: SIGNORINI, Inês (Org.). Linguagem e identidade: elementos para uma discussão no campo aplicado. Campinas: Mercado de Letras; São Paulo: Fapesp, 1998.

SERRANI-INFANTE, S. Identidade e Segundas Línguas. As Identificações no Discurso. In: SIGNORINI, Inês (Org.). Linguagem e identidade. Campinas: Mercado de Letras; São Paulo: Fapesp, 1998. SILVA, C. M. da. A Relação entre sujeitos e línguas em diferentes processos de imigração no sul de Minas Gerais. Dissertação de Mestrado em Ciências da Linguagem. Univás, 2012.

SILVA, L. O Papel da Memória Discursiva na Leitura. Crônicas de Clarice Lispector lidas por alunos do Ensino Médio. Dissertação de Mestrado em Ciências da Linguagem. Univás, 2012.

SOUZA, C. V. N. Lingua nacional, língua materna e processos identificatórios na alfabetização. Dissertação de Mestrado em Ciências da Linguagem. Univás, 2010. 